\title{
Overexpression of Livin promotes migration and invasion of colorectal cancer cells by induction of epithelial-mesenchymal transition via NF- $\kappa B$ activation
}

\author{
This article was published in the following Dove Press journal: \\ OncoTargets and Therapy \\ 29 February 2016 \\ Number of times this article has been viewed
}

Yang Ge',2
Xiankui Cao'
Dalu Wang'
Wei Sun'
Hongli Sun'
Bing Han'
Junpeng Cui'
Baolin Liu'
'The Sixth Department of General
Surgery, Shengjing Hospital of
China Medical University, Shenyang,
'Department of General Surgery,
General Hospital Under the Fushun
Mining Affairs Bureau, Fushun,
${ }^{3}$ The Eighth Department of General
Surgery, Shengjing Hospital of China
Medical University, Shenyang, Liaoning,
People's Republic of China

Yang $\mathrm{Ge}^{1,2}$

Xiankui Cao'

Dalu Wang

Wei Sun

Hongli Sun

Bing Han

Junpeng Cui

'The Sixth Department of General

${ }^{2}$ Department of General Surgery,

General Hospital Under the Fushun

People's Republic of China

Correspondence: Baolin Liu

The Sixth Department of General

Surgery, Shengjing Hospital of China

Medical University, 36 Sanhao Street,

Shenyang, Liaoning I I 0004,

People's Republic of China

Email baolinliu7I6@I63.com

\begin{abstract}
Livin is a novel member of the inhibitors of apoptosis protein family and has been implicated in the development and progression of colorectal cancer (CRC). However, the underlying mechanisms of Livin in CRC remain not fully understood. In this study, we investigated the effects of Livin expression on the proliferation and metastasis of CRC cells and also addressed its related molecular mechanism to metastasis. The expression of Livin in CRC cells (HCT116, SW480, and HT-29 cell lines) was determined by Western blot analysis. Our results show that the overexpression of Livin significantly promotes the proliferation, migration, and invasion of SW480 cells. Concurrently, the inhibition of Livin reduces the proliferation, migration, and invasion of HCT116 cells. In addition, Livin overexpression promotes the epithelialmesenchymal transition, as evidenced by a decrease in epithelial E-cadherin expression and an increase in mesenchymal markers, including vimentin, Slug, and Snail. Furthermore, adding the NF-KB inhibitor, BAY 11-7028, or transfecting with small interfering RNA against p65 notably restores the expression level of E-cadherin and attenuates the invasive ability of Livinoverexpressing cells. Taken together, these results indicate that Livin potentiates migration and invasion of CRC cells partially through the induction of epithelial-mesenchymal transition via $\mathrm{NF}-\kappa \mathrm{B}$ activation. Livin may be a potential therapeutic target for CRC.
\end{abstract}

Keywords: Livin, colorectal cancer, migration, invasion, epithelial-mesenchymal transition, NF- $\kappa \mathrm{B}$

\section{Introduction}

Despite advances in cancer therapies, colorectal cancer (CRC) remains one of the most common and lethal tumors worldwide, with an estimated 1,200,000 new cases and 600,000 deaths every year. ${ }^{1,2}$ Moreover, like the other tumors, metastasis remains the major cause of CRC-related death. ${ }^{3}$ Metastasis renders primary tumors to the secondary metastatic sites, such as liver and lungs. ${ }^{4}$ Therefore, understanding the mechanisms involved in CRC metastasis is of great importance and may provide promising therapeutic targets for CRC.

Livin is a novel member of the inhibitors of apoptosis protein family, which selectively binds to the apoptotic regulators, including SMAC, caspase-3, caspase-7, and caspase-9, results in the inactivation and degradation of these enzymes, and finally inhibits cell apoptosis. ${ }^{5,6}$ A growing body of literature shows that Livin is abundantly expressed in tumor tissues but barely expressed in normal tissues, ${ }^{7-9}$ indicating an important role of Livin in cancer progression. More recently, Livin was 
shown to impact on multiple cellular behaviors, such as cell proliferation, invasiveness, and motility. ${ }^{10}$ Given the pleiotropic actions of Livin, it is now considered as a promising target for cancer treatment. ${ }^{5,11}$ In CRC, Livin expression is upregulated in colorectal carcinoma tissues and might correlate with CRC metastasis and prognosis. ${ }^{12-14}$ Myung et al recently demonstrated that Livin was associated with tumor stage and facilitated tumor progression via regulating cell motility and apoptosis in CRC. ${ }^{15}$ However, the molecular mechanisms of Livin's involvement in the CRC metastasis remain to be elucidated.

In this study, we investigated the metastatic role of Livin and its underlying mechanism in CRC cells. Our results showed that Livin overexpression facilitates the migration, invasion, and epithelial-mesenchymal transition (EMT) of CRC cells. Furthermore, Livin-mediated EMT and metastasis was depen-

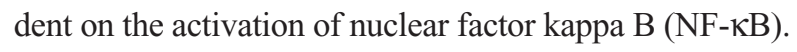

\section{Methods}

\section{Cell culture}

Three human CRC cell lines, namely HCT116, SW480, and HT-29 (Cell Bank of Chinese Academy of Sciences, Shanghai, People's Republic of China), were cultured in Dulbecco's Modified Eagle's Medium (Thermo Fisher Scientific, Waltham, MA, USA) containing 10\% fetal bovine serum (FBS; Hyclone, Logan, UT, USA). The cells were maintained at $37^{\circ} \mathrm{C}$ in a humidified atmosphere containing $5 \% \mathrm{CO}_{2}$ for subsequent experiments. The use of human CRC cell lines was approved by the ethics committee of China Medical University.

\section{Plasmid construction and generation of Livin-overexpressing SW480 cell line}

The coding sequence of Livin was obtained using reverse transcription-polymerase chain reaction (PCR) and was subsequently cloned into pcDNA3.1 vector. After sequencing confirmation, the SW480 cells were transfected with vector-Livin or vector empty using Lipofectamine 2000 Reagent (Life Technologies, Carlsbad, CA, USA) following the manufacturer's instructions. Twenty-four hours after transfection, G418 (Life Technologies) solution was added to the culture to screen Livin- or vector-transfected cell clones.

\section{RNA interference}

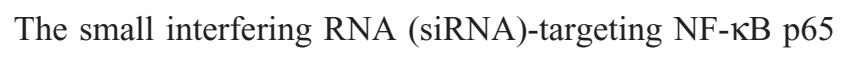
(p65 siRNA) and scrambled control siRNA (GenePharma, Shanghai, People's Republic of China) were transiently transfected into SW480 cells using Lipofectamine 2000 Reagent (Life Technologies). The short hairpin RNA (shRNA) construct-targeting Livin mRNA and scrambled control shRNA were transiently transfected into HCT116 cells using Lipofectamine 2000 Reagent (Life Technologies). The sequences of Livin shRNA are 5'-GATCCCCGGTGA GGTGCTTCTTCTGCTTCAAGAGAGCAGAAGAAGCA CCTCACCTTTTT-3', and the sequences of control shRNA are 5'-GATCCCCTTCTCCGAACGTGTCACGTTTCAAG AGAACGTGACACGTTCGGAGAATTTTT-3'.

\section{Real-time (RT)-PCR}

Total RNA from cells was extracted using a RNA simple Total RNA Kit (TIANGEN Co., Beijing, People's Republic of China). The RNA was then converted into complementary DNA using Super M-MLV Reverse Transcriptase (BioTeke, Beijing, People's Republic of China). The specific primers used for Livin and $\beta$-Actin were as follows: Livin, 5'-CAGTTCCTGCTCCGGTCAA-3' (forward) and 5'-GGGCTCAAGAACCCACCAC-3' (reverse); $\beta$-Actin, 5'-CTTAGTTGCGTTACACCCTTTCTTG-3' (forward) and 5'-CTGTCACCTTCACCGTTCCAGTTT-3' (reverse). The amplified products were quantitated with SYBR Green fluorescence (Solarbio, Beijing, People's Republic of China) in an ExicyclerTM 96 RT-PCR machine (Bioneer, Daejeon, Korea).

\section{Western blot analysis}

Cell lysis was prepared using the radioimmunoprecipitation analysis (RIPA) lysis buffer (Beyotime Institute of Biotechnology, Haimen, People's Republic of China). The protein concentration was determined using the bicinchoninic acid kits (Beyotime Institute of Biotechnology). Equal amounts of protein samples were separated by sodium dodecyl sulfate polyacrylamide gel electrophoresis (SDS-PAGE) $(8 \%$ or $10 \%$ gel) and electrotransferred onto polyvinylidene fluoride membranes (EMD Millipore, Billerica, MA, USA). After blocking with $5 \%$ nonfat milk at room temperature for 1 hour, the membranes were incubated with specific primary antibodies (anti-Livin, 1:1,000, Abcam, Cambridge, UK; anti-MMP-2, anti-E-cadherin, and anti-p65, 1:400, Boster, Wuhan, People's Republic of China; anti-vimentin, anti-Slug, anti-Snail, and anti-Histone H3, 1:500, Bioss, Beijing, People's Republic of China; and anti- $\beta$-Actin, 1:1,000, Santa Cruz Biotechnology Inc., Dallas, TX, USA) at $4{ }^{\circ} \mathrm{C}$ overnight. The membranes were rinsed with Tween-Tris buffered saline (TTBS) three times and then incubated with appropriate secondary antirabbit or antimouse immunoglobulin G-horseradish peroxidase (IgG-HRP) antibody (1:5,000 diluted; Beyotime Institute of Biotechnology). The targeted protein bands were visualized using an enhanced chemiluminescence reagent (Qihai Biotec, Shanghai, People's Republic of China) and analyzed using the Gel-Pro Analyzer software. 


\section{Colony formation assay}

Briefly, the SW480, vector control, and Livin-overexpressing cells were seeded as single cells in $35 \mathrm{~mm}$ dishes (100 cells per dish) and cultured for 14 days until the cell colonies were visible. The colonies were fixed with $4 \%$ paraformaldehyde and stained with Giemsa solution. The colonies consisting of at least 50 cells were counted under a phase contrast microscope (Motic, Xiamen, People's Republic of China). Colony formation efficiency was calculated as follows: (number of colonies/number of cells inoculated) $\times 100 \%$.

\section{MTT assay}

The cells were seeded in 96-well plates at a density of $2 \times 10^{3}$ cells in each well and incubated for various time intervals $(24,48,72$, or 96 hours). Then the cells were treated with $0.2 \mathrm{mg} / \mathrm{mL}$ of 3-(4,5-dimethylthiazol-2-yl)-2, 5-diphenyltetrazolium bromide (MTT; Sigma-Aldrich Co., St Louis, MO, USA) for an additional 4 hours of incubation. Finally, the cell supernatant was removed, and the resulting formazan was dissolved in $200 \mu \mathrm{L}$ of dimethylsulfoxide. The optical density was determined at $490 \mathrm{~nm}$ using a microplate reader.

\section{Wound-healing assay}

Cells were grown to $90 \%$ confluence in the plates. After aspirating the cell culture medium, a uniform wound was scratched on the cell monolayer using a $200 \mu \mathrm{L}$ sterile pipette tip. The remaining cells were then washed twice with serum-free culture media and cultured in a medium containing $10 \%$ FBS. The wound closure photographs were captured at 0 hour and 24 hours after scratching using a phase contrast microscope. The percent of wound closure was calculated as the cell migration distance to the initial wound distance.

\section{Transwell invasion assay}

The invasive capacities of CRC cells were determined using Matrigel (BD Biosciences, San Jose, CA, USA)-coated Transwell chambers ( $8 \mu \mathrm{m}$ pore size; Corning Incorporated, Corning, NY, USA). Briefly, the cells were resuspended with serum-free medium, $5 \times 10^{4}$ cells were seeded into the upper chamber, and the lower chamber was added with $800 \mu \mathrm{L}$ of DMEM containing 20\% FBS. After 24 hours of incubation, cells that remained on the upper chamber were scraped away with a cotton swab, and the cells that migrated to the bottom of the filter were fixed and stained with crystal violet dyes (AMRESCO, Solon, OH, USA). The number of invaded cells was photographed under an inverted phase contrast microscope.

\section{Immunofluorescence staining}

The distribution of E-cadherin and NF-אB p65 in SW480 cells was determined by immunofluorescence staining. Cells grown on the coverslips were fixed and permeabilized in $0.1 \%$ Triton X-100. After blocking with normal goat serum (Solarbio), the cell slides were incubated in anti-E-cadherin or anti-p65 antibody (dilution 1:200; Boster) at $4^{\circ} \mathrm{C}$ overnight. Subsequently, the cells were incubated with $\mathrm{Cy} 3$-labeled goat anti-rabbit secondary antibody (1:200; Beyotime Institute of Biotechnology) for 1 hour. After washing off the unbound secondary antibodies, all slides were counterstained with 4',6-diamidino-2-phenylindole. The images of stained slides were visualized under a laser scanning confocal microscope (Olympus, Tokyo, Japan)

\section{Electrophoretic mobility shift assay}

Nuclear extracts from SW480, Livin-transfected, or vectortransfected cells were prepared using a nuclear protein extraction kit (Beyotime Institute of Biotechnology). The binding reaction was performed using a Nonradioactive NF- $\kappa B$ EMSA Kit (Viagene Biotech, Changzhou, People's Republic of China). The core sequence of the probe-targeting $\mathrm{NF}-\mathrm{\kappa B}$ is $5^{\prime}$-AGTTGAGGGGACTTTCCCAGGC-3'. Five microliters of nuclear extracts (at a concentration of $5 \mu \mathrm{g} / \mu \mathrm{L}$ ) were incubated in $15 \mu \mathrm{L}$ of mixed binding buffer containing biotin-labeled NF- $\mathrm{KB}$ p 65 probe for 20 minutes at room temperature. The DNA/protein complexes were separated from free DNA on $6.5 \%$ nondenaturing polyacrylamide gel in $0.25 \mathrm{mM}$ tetrabromoethane (TBE) and electrotransferred onto a nylon membrane. After cross-linking using UV light for 30 minutes, the membranes were detected using streptavidin-HRP and an enhanced chemiluminescence solution (Qihai Biotec).

\section{Statistical analysis}

Data are presented as the mean \pm standard deviation. Oneway analysis of variance was used for the analyses between groups, and multiple comparisons were performed using the Bonferroni post hoc test. Data were processed using the GraphPad Prism 5.0 software (San Diego, CA, USA). A $P$-value $<0.05$ was considered statistically significant.

\section{Results Construction of stably Livin- overexpressing SW480 cell line}

To assess the functional role of Livin in CRC cells, we first examined the expression of Livin in three CRC cell lines and constructed a cell line that stably overexpressed Livin. As shown in Figure 1A, Livin expression was the lowest 
A
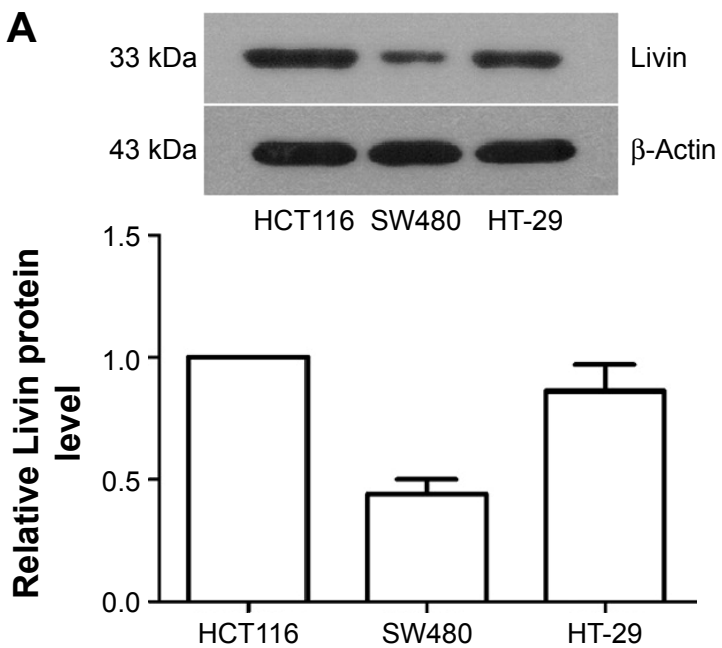

B

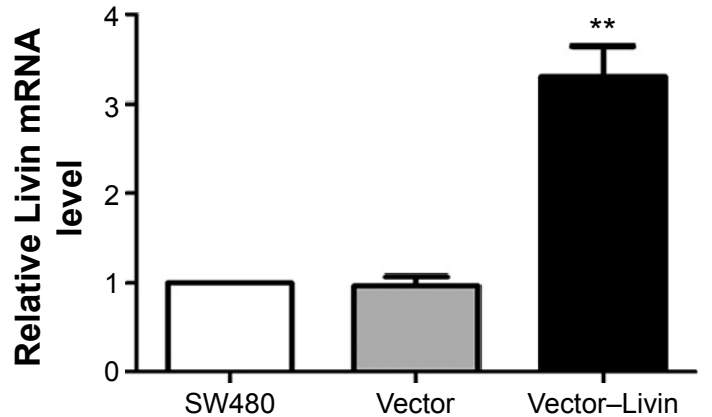

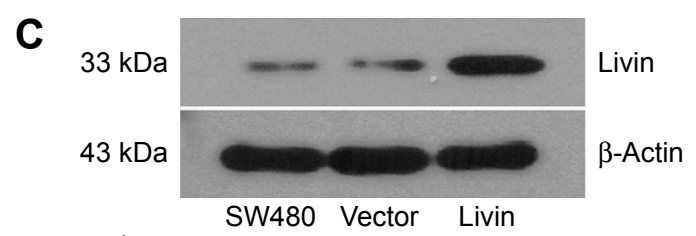

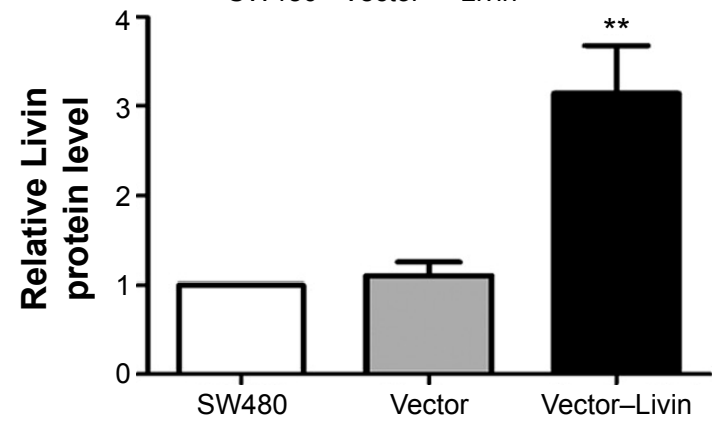

Figure I Constitutive overexpression of Livin in SW480 cells.

Notes: (A) Western blot analysis of Livin expression in HCTI 16, SW480, and HT-29 cell lines. (B) Real-time PCR analysis of the mRNA expression of Livin in the parental SW480, vector-transfected, and Livin-transfected cells. (C) Western blot analysis of Livin protein level in three groups of cells; the protein levels of Livin were quantified by a gray analysis with normalization to $\beta$-Actin. Compared to the vector control cells, ${ }^{*} * P<0.0$ I.

Abbreviation: PCR, polymerase chain reaction.

in SW480 cells and the highest in HCT116 cells among the cell lines tested. Thus, SW480 cells were chosen for Livin overexpression. After transfection, the mRNA level of Livin was significantly increased in Livin-transfected cells, which was about three times that of the vector control cells (Figure 1B, $P<0.01$ ). Similarly, Western blot results also revealed a marked upregulation of Livin protein level in Livin-transfected cells (Figure $1 \mathrm{C}, P<0.01$ ). The results indicated that a stable Livin-overexpressing SW480 cell line was constructed.

\section{Livin promotes the proliferation of SW480 cells}

The effect of Livin overexpression on cellular proliferation was determined by colony formation and MTT assays.
The colony formation assay showed more colonies of the Livin-transfected cells in the plate (Figure 2A). MTT results indicated that fortified Livin expression increased the cell proliferation rate after 48 hours (Figure $2 \mathrm{~B}, P<0.05$ ), but there was no significant difference in proliferation between Livin-transfected and vector control cells at 24 hours.

\section{Overexpression of Livin promotes migration and invasion of SW480 cells}

It has been demonstrated that Livin not only affects cell apoptosis but is also involved in tumor cell metastasis. ${ }^{16,17}$ To assess the functional role of Livin in CRC metastasis, we compared the wound-healing migratory and Matrigel invasive capacities of Livin-transfected cells with those of vector control or parental SW480 cells. Wound-healing 
A
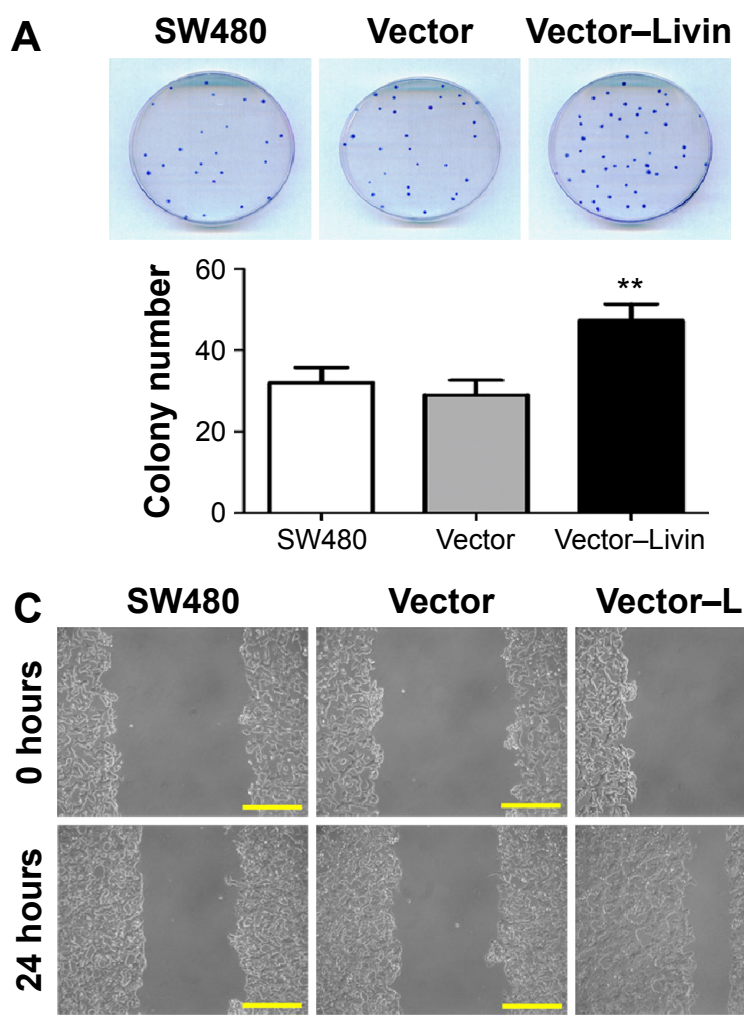

Vector-Livin

$\mathbf{E}$

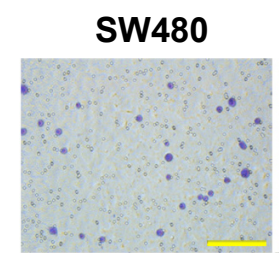

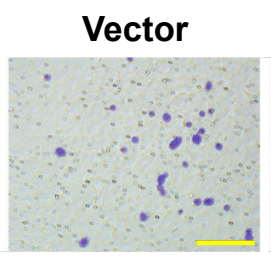

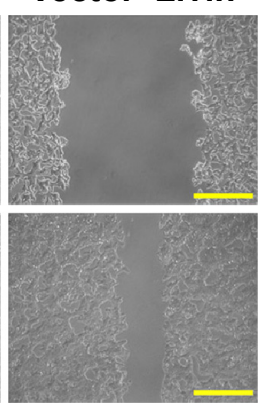

Vector-Livin

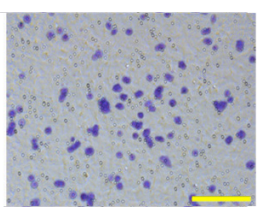

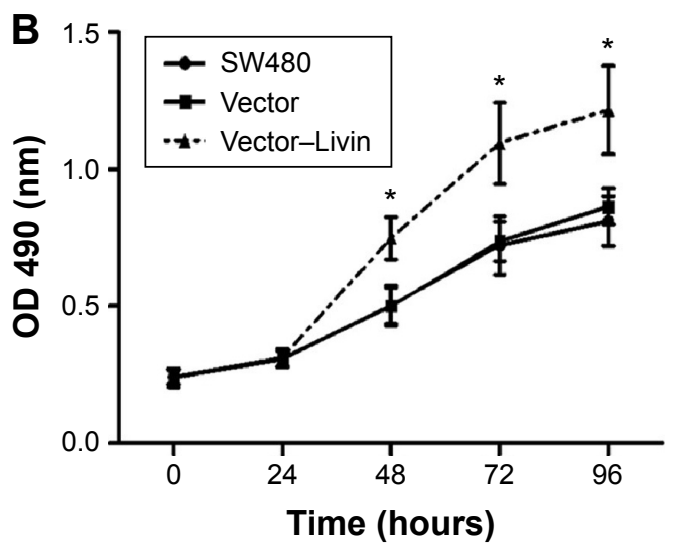
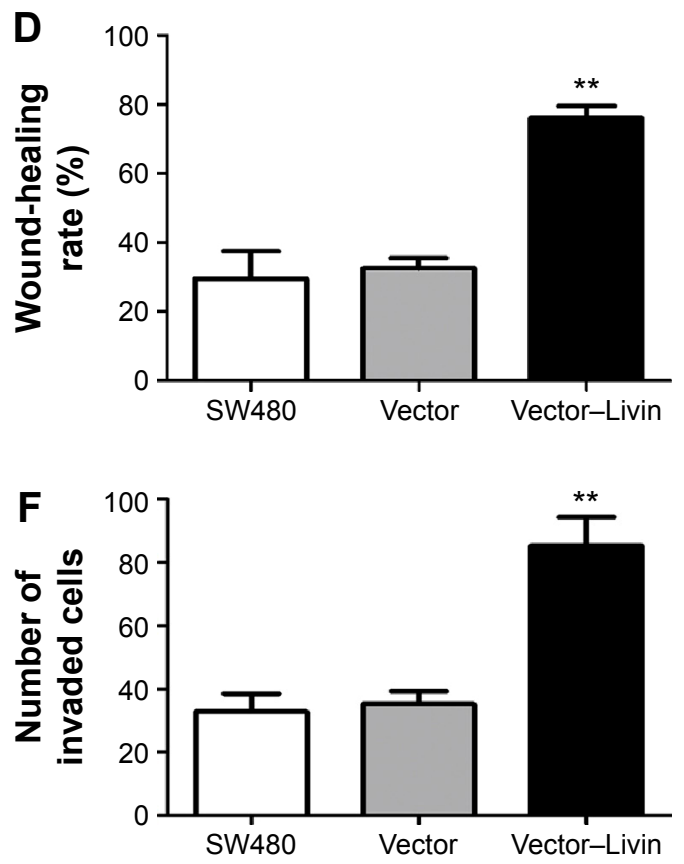

Figure 2 Overexpression of Livin promoting the proliferation, migration, and invasion of SW480 cells.

Notes: (A) Effect of Livin on single-cell proliferative capacity determined by colony formation assay. The cells on the plate were plotted as colony numbers. (B) Cell proliferation of the transfected cells and control assessed over 12-96 hours by an MTT assay. (C) Cell migration determined by the wound-healing assay. Magnification $\times 100$ and scale bars $=100 \mu \mathrm{m}$. (D) The percent of wound closure was calculated as the cell migration distance to the initial wound distance. (E) Transwell invasion assay to evaluate cell invasive ability. Magnification $\times 200$ and scale bars $=50 \mu \mathrm{m}$. (F) The number of invaded cells was calculated under an inverted light microscope. Data are presented as mean \pm SD; compared with the vector control cells, $* P<0.05$ and $* * P<0.01$.

Abbreviations: MTT, 3-(4,5-dimethylthiazol-2-yl)-2,5-diphenyltetrazolium bromide; OD, optical density; SD, standard deviation.

assay results showed that Livin-transfected cells exhibited enhanced migratory capacity compared to the vector control cells (Figure $2 \mathrm{C}$ and $\mathrm{D}, P<0.01$ ). Transwell invasion assay showed that more Livin-transfected cells penetrated through the Matrigel-coated chambers (Figure 2E and F, $P<0.01$ ), indicating that Livin overexpression increased the motility and invasive capacity of SW480 cells.

\section{Downregulation of Livin inhibits migration and invasion of HCTI I 6 cells}

To confirm the metastatic role of Livin in CRC cells, we further used shRNA to knockdown Livin expression in HCT116 cells. As shown in Figure 3A and B, significant reduction in the mRNA and protein levels of Livin was found in Livin shRNA-transfected HCT116 cells as determined by RT-PCR and Western blot analyses ( $P<0.01$ vs control cells). Consistently, knockdown of Livin caused a notable reduction in cell proliferation after 48 hours (Figure 3C). Furthermore, silencing of Livin expression dramatically inhibited the cell motility in wound-healing assay (Figure 3D) and the invasiveness in Transwell invasion assay (Figure 3E). Taken together, these results demonstrate that the knockdown of Livin inhibits CRC cell metastasis, highlighting the metastatic role of Livin in CRC cells. 
A

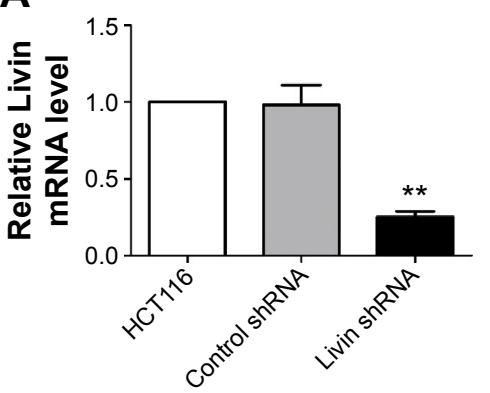

D

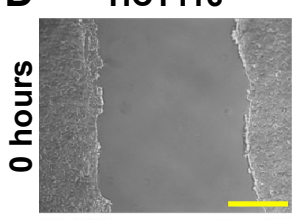

Control shRNA
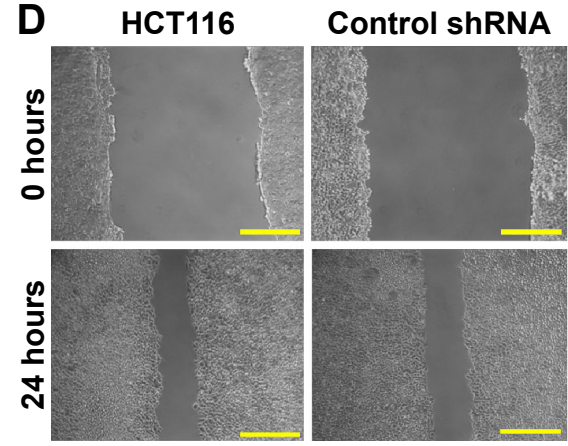

E

HCT116

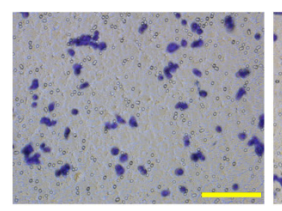

B

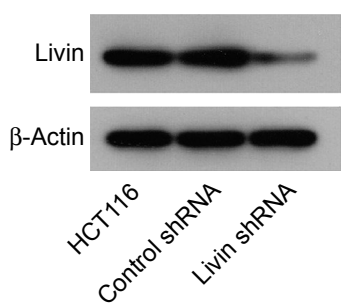

\section{Livin siRNA}
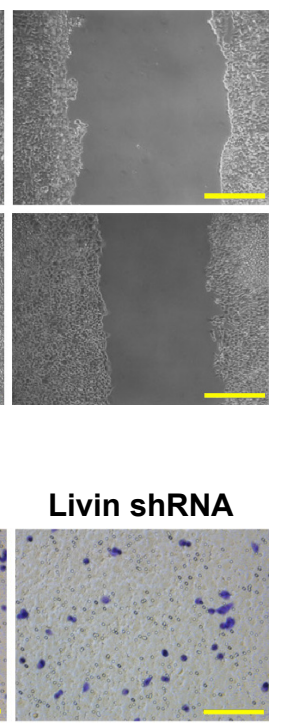

C
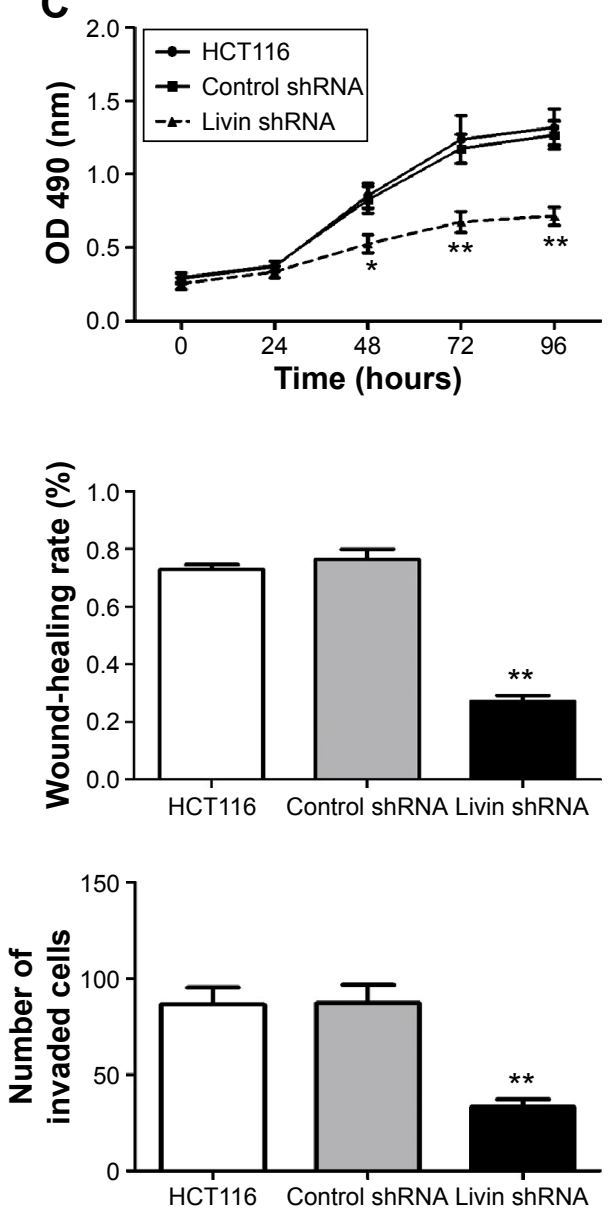

Figure 3 Downregulation of Livin inhibiting migration and invasion of HCTII6 cells.

Notes: (A) Real-time PCR analysis of Livin mRNA levels from HCTII6 cells transfected with shRNA against Livin or control shRNA. (B) Western blot analysis of Livin protein levels in HCTII6 cells. $\beta$-Actin was used as a loading control. (C) MTT assay for cell proliferation of parental HCTII6 cells or HCTII6 transfectants. (D) Cell migration determined by the wound-healing assay. Magnification $\times 100$ and scale bars $=100 \mu \mathrm{m}$. The percent of wound closure was calculated as the cell migration distance to the initial wound distance. (E) Transwell invasion assay performed to evaluate cell invasive ability. Magnification $\times 200$ and scale bars $=50 \mu \mathrm{m}$. The number of invaded cells was calculated under an inverted light microscope. Data are presented as mean $\pm S D$; compared with the control shRNA cells, $* P<0.05$ and $* * P<0.01$.

Abbreviations: MTT, 3-(4,5-dimethylthiazol-2-yl)-2,5-diphenyltetrazolium bromide; OD, optical density; PCR, polymerase chain reaction; shRNA, short hairpin RNA; $\mathrm{SD}$, standard deviation.

\section{Livin promotes the expression of EMT- related markers in SW480 cells}

Considering that EMT is a crucial step for mediating cancer metastasis, we further determined whether Livin overexpression affects the expression of EMT-related markers in SW480 cells. Our results showed that the overexpression of Livin significantly decreased the epithelial E-cadherin protein level but upregulated the expression levels of mesenchymal marker vimentin and the related transcription factors, including Snail and Slug in Livin-transfected cells (Figure $4 \mathrm{~A}$ and $\mathrm{B}, P<0.01$ vs vector group). Consistently, immunofluorescence staining also revealed a reduction of E-cadherin expression in Livin-transfected cells (Figure 4C). Together, these data suggest that Livin overexpression promotes the EMT in CRC cells, which might further mediate cell migration and invasion.

\section{Livin activates the NF- $\kappa B$ pathway in SW480 cells}

The NF- $\mathrm{KB}$ pathway has been shown to play a pivotal role in cancer metastasis. ${ }^{18}$ To assess whether Livin overexpression is related to NF- $\mathrm{\kappa B}$ activation, we further determined the expression and transcriptional activity of NF- $\kappa B$. Our data showed that the overexpression of Livin significantly increased the nuclear p65 levels as compared with that of the vector control cells (Figure 5A and B, $P<0.01$ ). Additionally, electrophoretic mobility shift assay (EMSA) results showed the low basal levels of NF- $\mathrm{KB}$-binding activity in parental SW480 and vector control cells, whereas the binding activity was significantly increased in Livin-transfected cells (Figure 5C and D, $P<0.01$ ). Immunofluorescence staining showed that Livin overexpression decreased the cytoplasmic p65 levels and increased the nuclear p65 levels as compared 
A

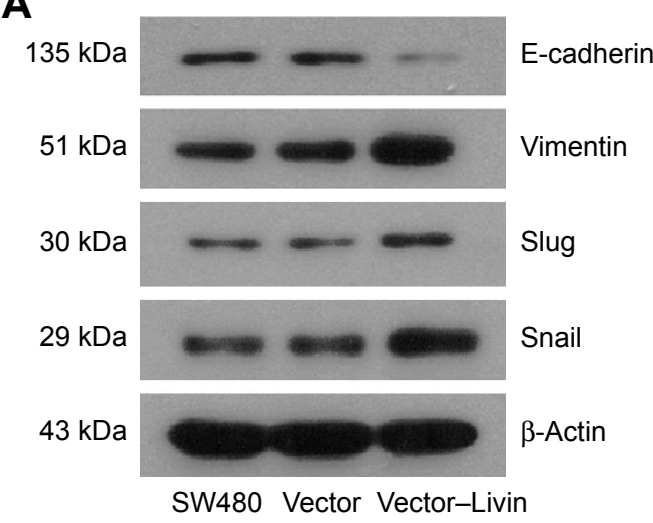

C

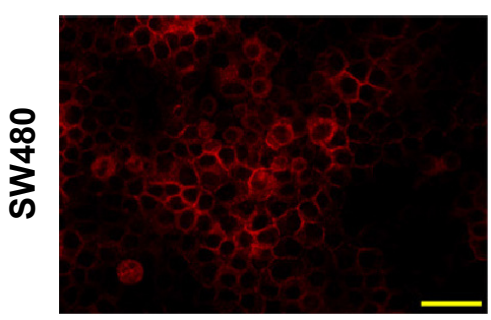

E-cadherin
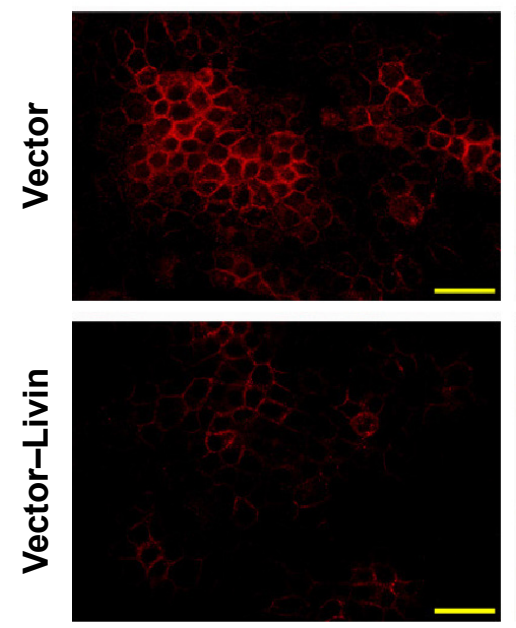

B
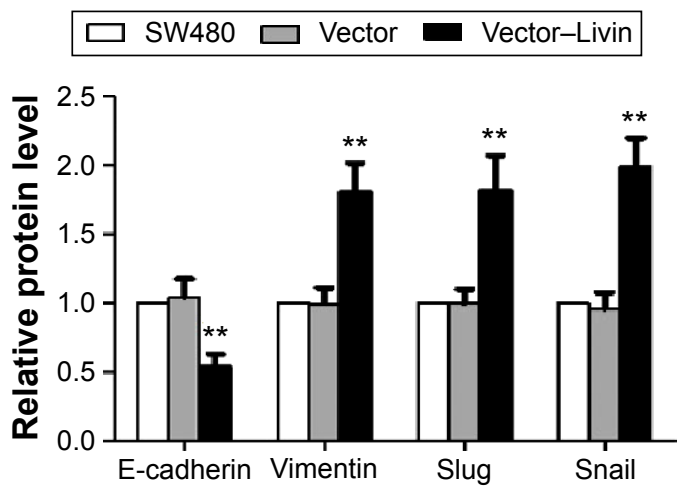

DAPI
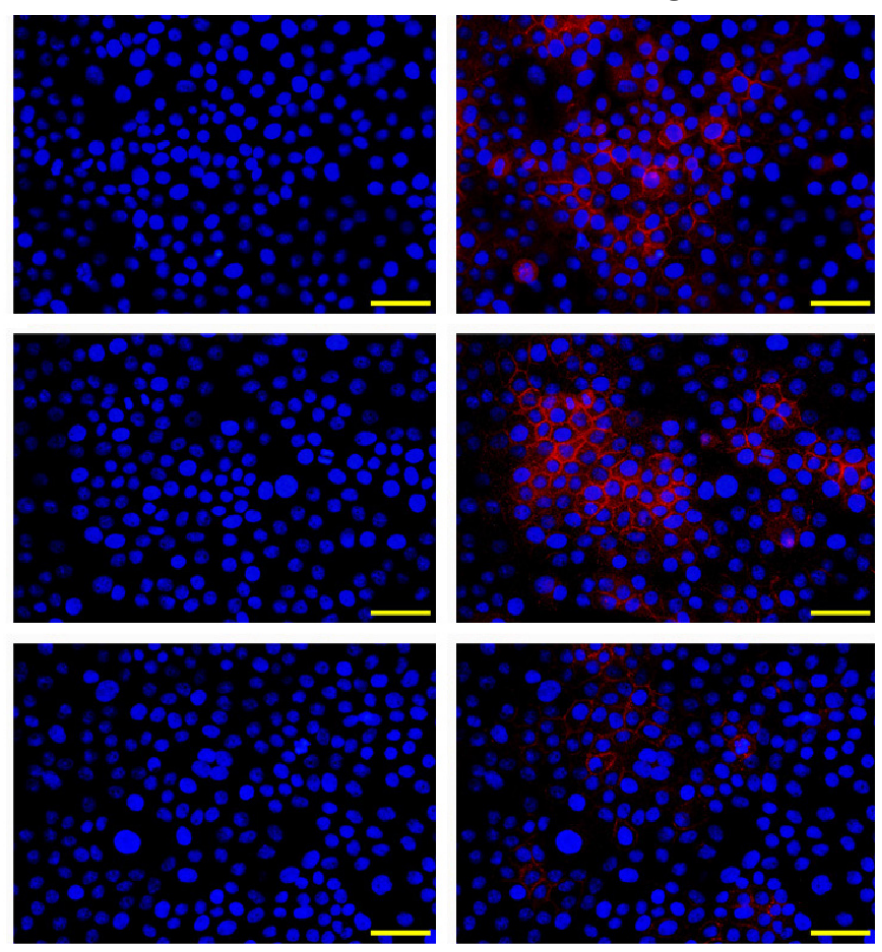

Figure 4 Livin promoting the expression of EMT-related markers in SW480 cells.

Notes: (A) Western blot analysis to determine the expression of EMT-related proteins, including E-cadherin, vimentin, Snail, and Slug, in SW480 cells. (B) Relative protein levels quantified by a gray analysis with normalization to $\beta$-Actin. (C) Expression of E-cadherin assessed by immunofluorescence staining, which shows a decrease in the E-cadherin level of Livin-overexpressed cells. Cell nuclei were visualized with 4',6-diamidino-2-phenylindole staining (blue). Magnification $\times 400$ and scale bars $=50 \mu \mathrm{m}$. Compared with the vector control cells $* * p<0.01$.

Abbreviations: EMT, epithelial-mesenchymal transition; NF- $\mathrm{kB}$, nuclear factor kappa B; siRNA, small interfering RNA.

to the parental SW480 and vector control cells (Figure 5E), which were consistent with Western blot and EMSA results. Taken together, these results indicate that Livin overexpression induces NF- $\mathrm{KB}$ activation in SW480 cells.

\section{NF- $\kappa B$ activation contributes to Livin- induced metastasis and EMT in CRC cells} To assess the involvement of NF- $\mathrm{KB}$ in Livin-induced CRC cell metastasis and EMT, we performed the in vitro inhibition assays using an NF- $\mathrm{KB}$ inhibitor and siRNAtargeting NF- $\mathrm{KB}$ p65. Western blot analysis showed that there was an obvious increase in NF- $\mathrm{B}$ p 65 with a concomitant decrease in E-cadherin levels in the Livin-transfected cells when compared to the vector or vector control siRNA cells (Figure 6A and B). Inhibition of NF- $\kappa B$ p65 by BAY 11-7028 or siRNA p65 significantly reduced the level of NF- $\mathrm{BB}$ p 65 and increased the level of E-cadherin as compared to the Livin-overexpressing cells (Figure 6A and $\mathrm{B}, P<0.05)$. Moreover, Transwell invasion assays revealed that the inhibition of $\mathrm{NF}-\kappa \mathrm{B}$ reversed the invasive ability induced by Livin overexpression (Figure 6C and D, $P<0.01)$. Overall, these data indicate that Livin-mediated 
A
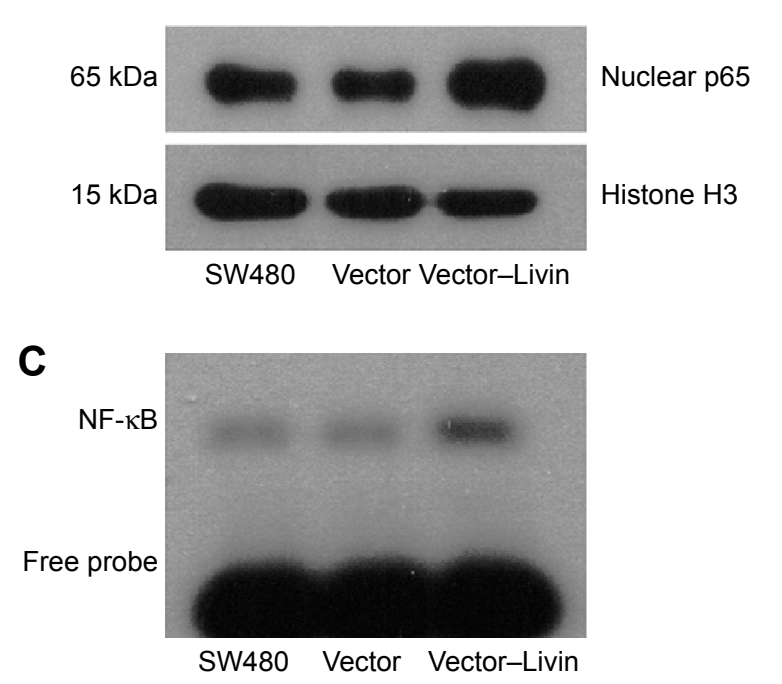

E
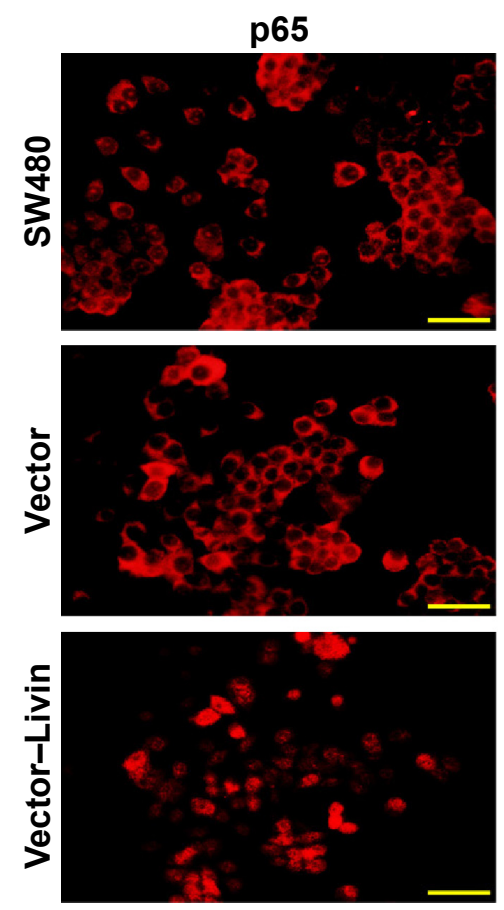

B
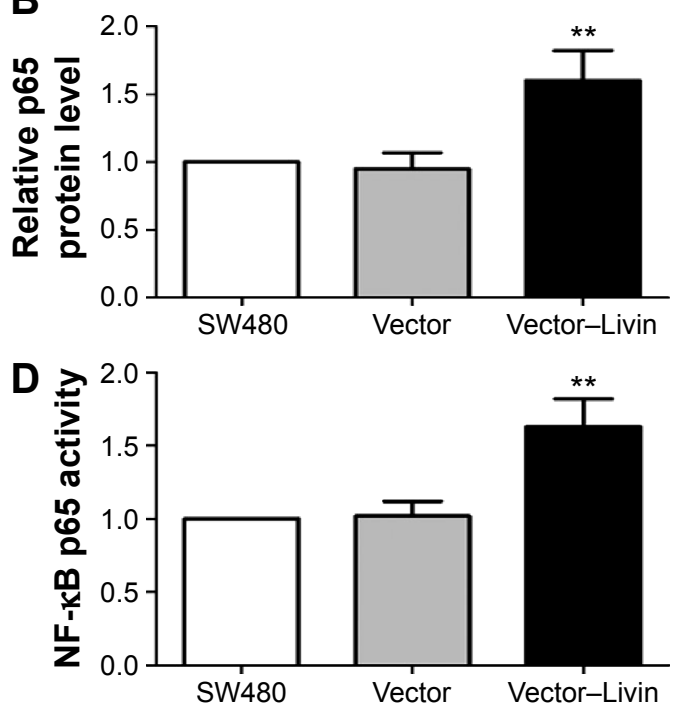

DAPI
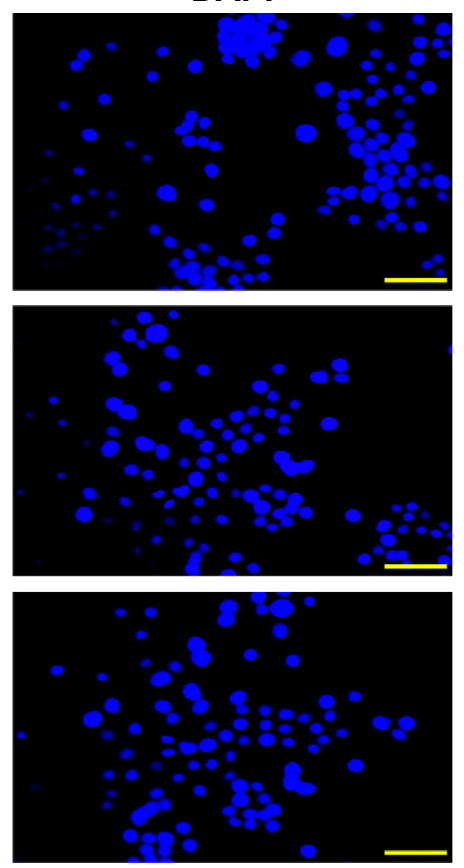
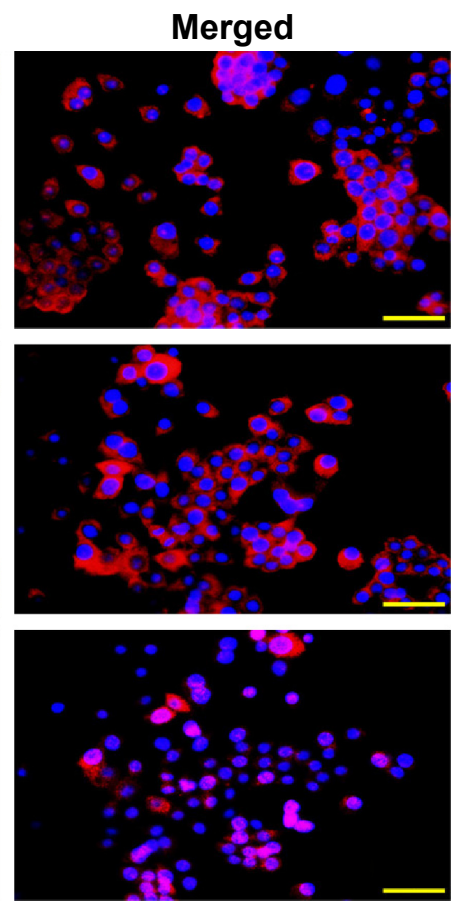

Figure 5 Livin activating the NF- $\mathrm{KB}$ pathway in SW480 cells.

Notes: (A) Expression level of nuclear p65 in SW480 cells detected by Western blot analysis, with the nuclear marker protein Histone H3 as loading control. (B) Relative

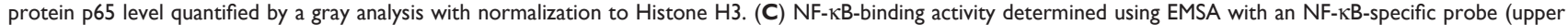
panel) and with a free probe (lower panel) as loading control. (D) Relative DNA-binding levels of NF- $\kappa B$. (E) Immunofluorescence staining of NF- $\kappa B$ p65 expression in the SW480 cells; representative images of cytoplasmic and nuclear NF- $\kappa B$ p 65 expression and localization. Magnification $\times 400$ and scale bars $=50 \mu \mathrm{m}$. Compared with the vector control cells, $* * P<0.01$.

Abbreviations: DAPI, 4',6-diamidino-2-phenylindole; EMSA, electrophoretic mobility shift assay; NF- $\kappa$ B, nuclear factor kappa B.

cellular metastasis and EMT are partially dependent on $\mathrm{NF}-\mathrm{\kappa B}$ activation.

\section{Discussion}

Livin, a novel member of the inhibitors of apoptosis protein family, has been implicated in the development and progression of various human cancers. In this study, we demonstrated the potential metastatic role of Livin in CRC cells. Livin significantly facilitated the proliferation, motility, and invasiveness of CRC cells. Furthermore, Livin overexpression induced EMT in SW480 cells, which was partially dependent on NF- $\kappa \mathrm{B}$ activation. These results indicate an important mediator of Livin in CRC cell migration and invasion. 


\section{A}

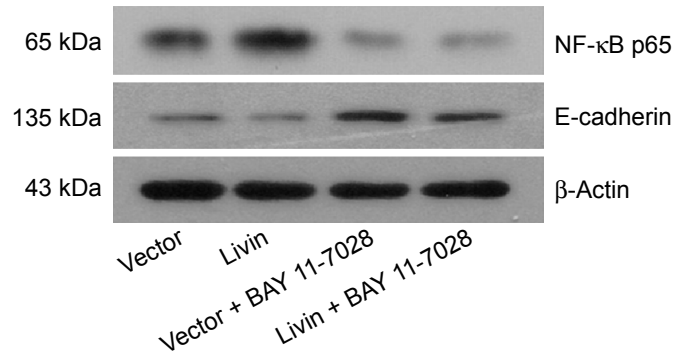

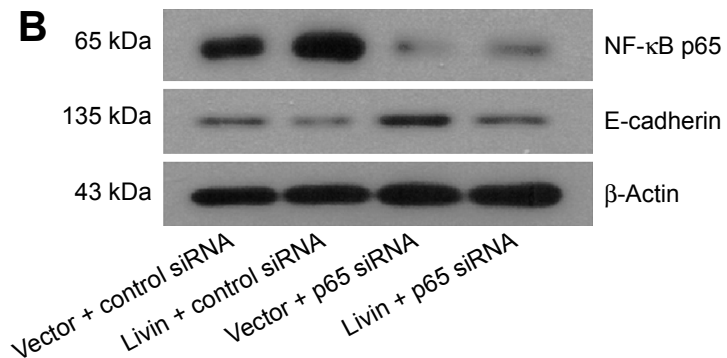
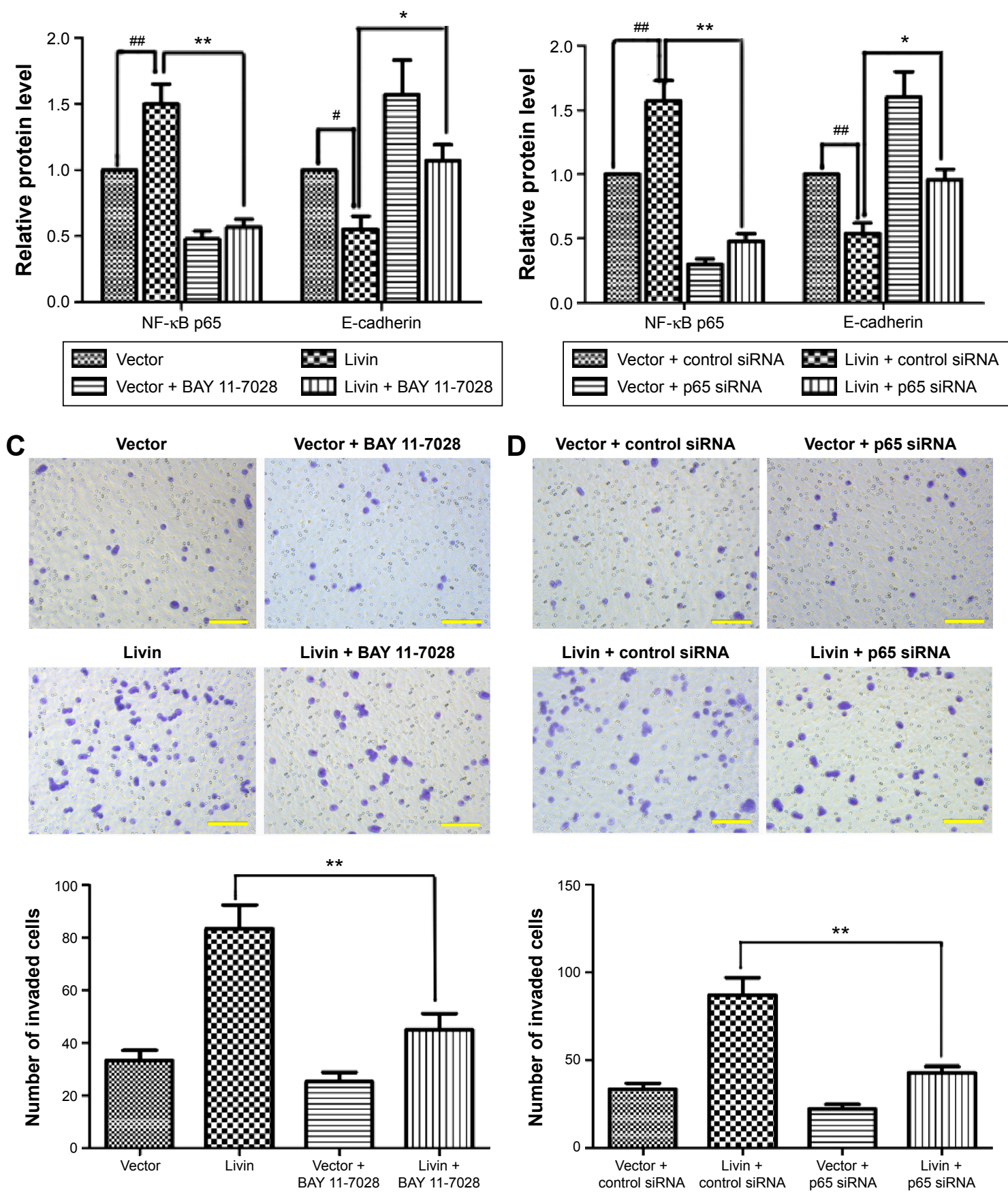

Figure $6 \mathrm{NF}-\kappa \mathrm{B}$ activation contributing to Livin-induced invasion and EMT.

Notes: Western blot analysis of NF- $\mathrm{KB}$ p65 and E-cadherin protein levels in SW480 cells treated with (A) BAY II-7028 or (B) siRNA p65. Relative protein levels were quantified by a gray analysis with normalization to $\beta$-Actin. Blocking the NF- $\kappa B$ pathway restored the expression of E-cadherin repressed by Livin. (C and D) Transwell invasion assay indicating that BAY II-7028 or siRNA p65 treatment suppresses Livin-induced invasive capacity of SW480 cells. Magnification $\times 200$ and scale bars $=50 \mu \mathrm{m}$. Compared to the vector cells or vector control siRNA cells, $\# P<0.01$; compared to the Livin cells or Livin control siRNA cells, $* P<0.05$ and $* * P<0.01$.

Abbreviations: DAPI, 4',6-diamidino-2-phenylindole; EMT, epithelial-mesenchymal transition; NF-KB, nuclear factor kappa B; siRNA, small interfering RNA. 
Previous studies have linked Livin to metastasis in multiple solid tumors, such as lung cancer, ${ }^{19}$ breast cancer, ${ }^{20,21}$ gastric cancer, ${ }^{17}$ and laryngohypopharyngeal cancer. ${ }^{16}$ In $\mathrm{CRC}$, ectopic overexpression of Livin correlates with tumor metastasis and implies poor prognosis. ${ }^{12-14}$ Recently, Myung et al further demonstrated that Livin expression is associated with the tumor stage and facilitated tumor progression via regulating CRC cell motility and apoptosis. ${ }^{15}$ However, the metastatic mechanism of Livin in CRC cells still needs investigation. Here, we showed that Livin overexpression significantly increased the proliferation, migration, and invasion of SW480 cells. Concurrently, downregulation of Livin inhibited the cell proliferation rate and suppressed the motility and invasiveness in HCT116 cells. These results demonstrate that Livin promotes cell proliferation and metastasis in CRC cells, highlighting the metastatic role of Livin in CRC and establishing that our results are in line with those of a previous report. ${ }^{20}$

EMT occurs in the early stage of tumor metastasis and plays a key role in cancer progression. ${ }^{4,22}$ The hallmark features of EMT include reduction in cell adhesion and acquirement of cell motility. ${ }^{23}$ E-cadherin is the most vital epithelial marker, which can be repressed by the transcriptional repressors, such as Snail and Slug. ${ }^{24,25}$ Vimentin is one of the mesenchymal markers during EMT. In this study, ectopic overexpression of Livin resulted in a significant downregulation of E-cadherin and upregulation of vimentin, Snail, and Slug at the protein levels in Livin-overexpressed SW480 cells. Immunofluorescence analysis also confirmed the decreased E-cadherin expression in Livin-overexpressed SW480 cells. Our results are in line with those of a recent study showing Livin-induced EMT in breast cancer cells ${ }^{21}$ and highlight a functional link between Livin and EMT in CRC cell metastasis.

Multiple pathways and molecules contribute to the EMT process, ${ }^{26,27}$ among which the NF- $\kappa \mathrm{B}$ pathway has been shown to play an essential role for EMT process. NF- $\mathrm{BB}$ can regulate the expression of EMT-related proteins, such as Snail, Slug, Twist, and Zeb1. ${ }^{18,28} \mathrm{NF}-\kappa \mathrm{B}$ closely correlates with cancer development and progression. ${ }^{29,30}$ Recently, Chen et al found that Livin regulated invasion of prostate cancer cells via the NF- $\mathrm{BB}$ signaling pathway. ${ }^{31}$ In this study, we found that the overexpression of Livin resulted in cytoplasmic $\mathrm{NF}-\kappa \mathrm{B}$ p65 translocation to the nucleus of CRC cells. In addition, Livin increased the NF- $\kappa \mathrm{B}-$ binding activity, suggesting the activation of $\mathrm{NF}-\kappa \mathrm{B}$ in the Livin-overexpressing cells. Furthermore, by using the NF- $\mathrm{B}$ inhibitor BAY 11-7028, we found that NF- $\kappa B$ inhibition restored the expression level of E-cadherin and inhibited the invasiveness of
Livin-overexpressed cells. Similar results were observed in the siRNA-mediated NF- $\mathrm{B}$ knockdown experiment. Our results suggest that Livin-induced EMT is at least partially dependent on NF- $\kappa \mathrm{B}$ activation. Yet, it is also noteworthy that Livin regulated EMT in breast cancer cells through AKT (the serine/threonine kinase), also konwn as protein kinase B (PKB) signaling; ${ }^{21}$ further characterizations are required to illustrate the mechanisms related to Livin-induced EMT.

\section{Conclusion}

In summary, we demonstrated that Livin contributes to CRC cells' migration, invasion, and EMT. The activation of NF- $\mathrm{BB}$ is at least partially responsible for Livin-induced EMT. Our results indicate a critical role of Livin in the regulation of $\mathrm{CRC}$ metastasis, which may provide a potential target for CRC therapy.

\section{Disclosure}

The authors report no conflicts of interest in this work.

\section{References}

1. Jemal A, Bray F, Center MM, Ferlay J, Ward E, Forman D. Global cancer statistics. CA Cancer J Clin. 2011;61(2):69-90.

2. Labianca R, Merelli B. Screening and diagnosis for colorectal cancer: present and future. Tumori. 2010;96(6):889-901.

3. Jemal A, Siegel R, Ward E, Hao Y, Xu J, Thun MJ. Cancer statistics, 2009. CA Cancer J Clin. 2009;59(4):225-249.

4. Gavert N, Ben-Ze'ev A. Epithelial-mesenchymal transition and the invasive potential of tumors. Trends Mol Med. 2008;14(5):199-209.

5. Chang H, Schimmer AD. Livin/melanoma inhibitor of apoptosis protein as a potential therapeutic target for the treatment of malignancy. Mol Cancer Ther. 2007;6(1):24-30.

6. Salvesen GS, Duckett CS. IAP proteins: blocking the road to death's door. Nat Rev Mol Cell Biol. 2002;3(6):401-410.

7. Xi RC, Sheng YR, Chen WH, et al. Expression of survivin and Livin predicts early recurrence in non-muscle invasive bladder cancer. J Surg Oncol. 2013;107(5):550-554.

8. Gazzaniga P, Gradilone A, Giuliani L, et al. Expression and prognostic significance of LIVIN, SURVIVIN and other apoptosis-related genes in the progression of superficial bladder cancer. Ann Oncol. 2003; 14(1):85-90.

9. Tanabe H, Yagihashi A, Tsuji N, Shijubo Y, Abe S, Watanabe N. Expression of survivin mRNA and Livin mRNA in non-small-cell lung cancer. Lung Cancer. 2004;46(3):299-304.

10. Liu H, Wang S, Sun H, et al. Inhibition of tumorigenesis and invasion of hepatocellular carcinoma by siRNA-mediated silencing of the livin gene. Mol Med Rep. 2010;3(6):903-907.

11. Nachmias B, Ashhab Y, Ben-Yehuda D. The inhibitor of apoptosis protein family (IAPs): an emerging therapeutic target in cancer. Semin Cancer Biol. 2004;14(4):231-243.

12. Wang Y, Li Y, Zhou B, et al. Expression of the apoptosis inhibitor Livin in colorectal adenoma-carcinoma sequence: correlations with pathology and outcome. Tumour Biol. 2014;35(12):11791-11798.

13. Xi RC, Biao WS, Gang ZZ. Significant elevation of survivin and Livin expression in human colorectal cancer: inverse correlation between expression and overall survival. Onkologie. 2011;34(8-9):428-432.

14. Li JH, He WJ, He YJ. [Expression and clinical significance of Survivin and Livin in DukesoB colorectal cancer]. Ai Zheng/Chin J Cancer. 2007;26(5):547-551. Chinese. 
15. Myung DS, Park YL, Chung CY, et al. Expression of Livin in colorectal cancer and its relationship to tumor cell behavior and prognosis. PLOS One. 2013;8(9):e73262.

16. Yoon TM, Kim SA, Lee DH, et al. Expression of Livin and the inhibition of tumor progression by Livin silencing in laryngohypopharyngeal cancer. In Vivo. 2014;28(5):751-759.

17. Ou JM, Ye B, Qiu MK, et al. Knockdown of Livin inhibits growth and invasion of gastric cancer cells through blockade of the MAPK pathway in vitro and in vivo. Int J Oncol. 2014;44(1):276-284.

18. Min C, Eddy SF, Sherr DH, Sonenshein GE. NF-kappaB and epithelial to mesenchymal transition of cancer. J Cell Biochem. 2008; 104(3):733-744.

19. Lin X, Li HR, Lin XF, et al. Silencing of Livin inhibits tumorigenesis and metastasis via VEGF and MMPs pathway in lung cancer. Int $J$ Oncol. 2015;47(2):657-667.

20. Ghebeh H, Al-Khaldi S, Olabi S, et al. Fascin is involved in the chemotherapeutic resistance of breast cancer cells predominantly via the PI3K/Akt pathway. Br J Cancer. 2014;111(8):1552-1561.

21. Li F, Yin X, Luo X, et al. Livin promotes progression of breast cancer through induction of epithelial-mesenchymal transition and activation of AKT signaling. Cell Signal. 2013;25(6):1413-1422.

22. Cao H, Xu E, Liu H, Wan L, Lai M. Epithelial-mesenchymal transition in colorectal cancer metastasis: a system review. Pathol Res Pract. 2015; 211(8):557-569
23. Baum B, Settleman J, Quinlan MP. Transitions between epithelial and mesenchymal states in development and disease. Semin Cell Dev Biol. 2008;19(3):294-308.

24. Nieto MA. The ins and outs of the epithelial to mesenchymal transition in health and disease. Annu Rev Cell Dev Biol. 2011;27:347-376.

25. Sanchez-Tillo E, Liu Y, de Barrios O, et al. EMT-activating transcription factors in cancer: beyond EMT and tumor invasiveness. Cell Mol Life Sci. 2012;69(20):3429-3456.

26. Foroni C, Broggini M, Generali D, Damia G. Epithelial-mesenchymal transition and breast cancer: role, molecular mechanisms and clinical impact. Cancer Treat Rev. 2012;38(6):689-697.

27. Huber MA, Beug H, Wirth T. Epithelial-mesenchymal transition: NFkappaB takes center stage. Cell Cycle. 2004;3(12):1477-1480.

28. Huber MA, Azoitei N, Baumann B, et al. NF-kappaB is essential for epithelial-mesenchymal transition and metastasis in a model of breast cancer progression. J Clin Invest. 2004;114(4):569-581.

29. Kojima M, Morisaki T, Sasaki N, et al. Increased nuclear factor-kB activation in human colorectal carcinoma and its correlation with tumor progression. Anticancer Res. 2004;24(2B):675-681.

30. Zubair A, Frieri M. Role of nuclear factor-kB in breast and colorectal cancer. Curr Allergy Asthma Rep. 2013;13(1):44-49.

31. Chen F, Yang D, Wang S, et al. Livin regulates prostate cancer cell invasion by impacting the NF-kappaB signaling pathway and the expression of FN and CXCR4. IUBMB Life. 2012;64(3):274-283.
OncoTargets and Therapy

\section{Publish your work in this journal}

OncoTargets and Therapy is an international, peer-reviewed, open access journal focusing on the pathological basis of all cancers, potential targets for therapy and treatment protocols employed to improve the management of cancer patients. The journal also focuses on the impact of management programs and new therapeutic agents and protocols on

\section{Dovepress}

patient perspectives such as quality of life, adherence and satisfaction. The manuscript management system is completely online and includes a very quick and fair peer-review system, which is all easy to use. Visit http://www.dovepress.com/testimonials.php to read real quotes from published authors. 